\title{
Oral health conditions in children with idiopathic nephrotic syndrome: a cross- sectional study
}

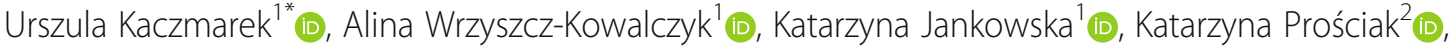 \\ Monika Mysiak-Dębska ${ }^{1}$ (D) Iwona Przywitowska ${ }^{1}$ (i) and Irena Makulska² (i)
}

\begin{abstract}
Background: Nephrotic syndrome is one of the chronic illnesses in the pediatric age group. The aim of this study was to assess the oral health of patients with steroid-sensitive idiopathic nephrotic syndrome (iNS).

Methods: A case-control study was performed on iNS patients and healthy from May 2018 to April 2019. Dental caries was assessed by the World Health Organization criteria, developmental defects of enamel by the mDDE index, oral hygiene by the OHI-S and API, and gingival condition by the Gl. Oral health behavior was recorded using a standardized questionnaire including tooth brushing, fluoride prevention, dietary habits and utilization of dental care. Additionally, Streptococcus mutans (SM) and Lactobacillus spp. (LB) bacteria in saliva were assessed using the CRT bacteria test. Statistical analysis comparing oral health parameters was carried by Pearson's chisquared, Fisher's exact, Shapiro-Wilk verified by Student's t or Mann-Whitney U tests.

Results: The study included 94 participants of both sexes at the age of 4 to 17 years ( 47 cases and 47 controls) who were treated in Clinic of Pediatric Nephrology or outpatients' dental clinic in Wroclaw, Poland. The iNS patients compared to the controls revealed some lower caries experience (83.0\% vs $95.7 \%)$ and number of caries affected primary and/or permanent teeth (4.6 \pm 3.5 vs $6.0 \pm 4.1)$, a significantly lower number of filled primary and/or permanent teeth $(1.1 \pm 1.6$ vs $3.5 \pm 3.0, P<0.001)$ and higher incidence of enamel hypoplasia $(31.9 \%$ vs $4.3 \%, P<$ 0.001). The numbers of the iNS patients with high level of SM and LB were similar to the controls. The iNS patients had a higher OHI-S score $(1.89 \pm 1.59$ vs $1.05 \pm 1.02, P<0.010)$ and a higher $\mathrm{Gl}$ score $(0.7 \pm 1.0$ vs $0.3 \pm 0.6, P=0.050)$. Moreover, they less frequently brushed their teeth twice a day $(78.8 \%$ vs $93.6 \%, P=0.026)$ and more frequently consumed three or more snacks daily $(53.2 \%$ vs $23.4 \%, P=0.002)$.
\end{abstract}

Conclusions: The iNS patients despite the poor oral hygiene revealed lower caries experience but smaller number of restored caries-affected teeth, more severe gingivitis and more frequently teeth affected by enamel hypoplasia.

Keywords: Idiopathic nephrotic syndrome, Caries, Enamel hypoplasia, Oral hygiene, Gingival inflammation

\footnotetext{
* Correspondence: urszula.kaczmarek@umed.wroc.pl

'Department of Conservative Dentistry and Pedodontics, Wroclaw Medical University, Krakowska 26, 50-425 Wroclaw, Poland

Full list of author information is available at the end of the article
}

(c) The Author(s). 2020 Open Access This article is licensed under a Creative Commons Attribution 4.0 International License, which permits use, sharing, adaptation, distribution and reproduction in any medium or format, as long as you give appropriate credit to the original author(s) and the source, provide a link to the Creative Commons licence, and indicate if changes were made. The images or other third party material in this article are included in the article's Creative Commons licence, unless indicated otherwise in a credit line to the material. If material is not included in the article's Creative Commons licence and your intended use is not permitted by statutory regulation or exceeds the permitted use, you will need to obtain permission directly from the copyright holder. To view a copy of this licence, visit http://creativecommons.org/licenses/by/4.0/. The Creative Commons Public Domain Dedication waiver (http://creativecommons.org/publicdomain/zero/1.0/) applies to the data made available in this article, unless otherwise stated in a credit line to the data. 


\section{Background}

Nephrotic syndrome is a common chronic glomerular disease in childhood. Primary causes of the syndrome include minimal change disease, focal segmental glomerulosclerosis, membranous nephropathy, genetic disorders and secondary diseases linked to infections, drugs and neoplasia; however, it can also be idiopathic [1]. It presents itself as a combination of clinical and biochemical symptoms resulting from proteinuria, hypoproteinemia, hypoalbuminemia, hyperlipoproteinemia and an increase in cholesterol and triglycerides. Clinical symptoms include edema of the legs and hands or face, weight gain, feeling very tired, not feeling hungry and foamy or bubbly urine. The disease affects children of any age, from infancy to adolescence, however, predominantly between 1 and 6 years of age $[2,3]$. The worldwide prevalence of idiopathic nephrotic syndrome is approximately 16 cases per 100,000 children with an incidence of 2 to 7 per 100 , 000 children [1-3].

Nephrotic syndrome is classified by response or lack of response to a standardized corticosteroid therapy into steroid-sensitive and steroid-resistant types. The majority of patients are treated by corticosteroids administration and $80 \%$ of children respond to corticosteroid therapy. However, even steroid-sensitive types of the disease can have a frequently relapsing course, requiring administration of alternative immunosuppressive agents. Long-term prognosis for steroid-sensitive diseases is excellent, but steroid-resistant ones constitute a future risk of chronic or end-stage renal disease $[4,5]$. The frequent steroids administration may affect oral health adversely leading to candidiasis as well as an impairment of bone metabolism causing a considerable decrease in the mandibular bone mineral density [6-8].

The protocol of nephrotic syndrome therapy, except steroids, includes specific dietary regimes with a limitation of sodium, diuretics if edema and ascites, antibiotics in the case of infection. The prolonged administration of antibiotics (especially amoxicillin) can cause disturbances of hard dental tissues development, leading to defects of the enamel $[9,10]$. In young children with chronic renal disease, which is frequently accompanied by altered mineral metabolism, developmental defects of enamel will occur in early postnatal life. Patients with nephrotic syndrome show disturbance of calcium homeostasis due to hypocalcemia, reduced vitamin D metabolites in serum, weakened intestinal absorption of calcium and raised level of parathyroid hormone, which lead to abnormal bone histology. The changes are assigned to the loss of various plasma proteins and minerals in urine, and steroid therapy [11, 12]. Disturbances in calcium, phosphorus and vitamin D metabolism occurring during the formation of enamel in developing teeth can result in developmental defects of enamel as demonstrated by other studies $[13,14]$.

The priority and permanent concern for the general health can prone to neglect of oral condition care; it can lead to irregular teeth cleaning and dental check-ups. An occasional removal of dental biofilm promotes to its accumulation and can predispose to gingival inflammation, drug-induced gingival hyperplasia and an increase of destructive periodontal diseases $[6,15]$. However, the data on dental caries experience in young patients with nephrotic syndrome are scarce and inconsistent pointing on lower or greater caries occurrence $[16,17]$.

This study investigated selected oral health parameters in young participants suffering from idiopathic steroidsensitive nephrotic syndrome (iNS) and compared to healthy ones. The null hypothesis was there was no difference in the studied parameters between two groups.

\section{Material and methods Study design}

The study was an observational study comparing the oral condition in idiopathic steroid-sensitive nephrotic syndrome (iNS) patients treated in the Department and Clinic of Pediatric Nephrology with healthy outpatients attending to the dental clinic at the Department of Conservative Dentistry and Pedodontics of Wroclaw Medical University, Poland. The examinations were carried out from May 2018 to April 2019. The STROBE guidelines (Strengthening the Reporting of Observational Studies in Epidemiology) were followed [18].

\section{Participants}

The enrolled participants $(n=110)$ both male and female, were at the age of 4 to 17 years. However, $9.1 \%$ $(n=10)$ of the parents did not express consent to the study and $5.4 \%(n=6)$ of the sampled children refused to be examined. Therefore, 94 participants were finally included in the study. The patients with diagnosed idiopathic steroid-sensitive nephrotic syndrome $(n=47)$ in remission $(n=26)$ or relapse $(n=21)$ phases were selected from the pool of patients hospitalized in the Clinic of Pediatric Nephrology. The inclusive criteria were the disease lasting at least 2 years at the time of oral examination and no other acute systemic diseases currently present. The control group comprised clinically healthy participants $(n=47)$ with a negative history of renal disease and acute or chronic systemic diseases at the age range and sex corresponding to the iNS patients, who visited the outpatient dental clinic due to routine dental treatment or checkups. All participants involved in the study had to provide written informed consent of a parent (and consent of a patient at the age of 16 and over), a completed questionnaire, and cooperation during oral clinical examinations and the collection 
of saliva. The participants who did not fulfil the inclusion criteria were excluded from the study.

\section{Ethical permission}

The study protocol was approved by the Bioethics Committee of Wroclaw Medical University (permission no. KB-343/2016) in accordance with the Declaration of Helsinki. Participation in the study was voluntary and anonymous, and the collected data was treated confidentially.

\section{Sample size estimation}

Sample size determination was based on t-test for independent groups using a special computer program [19]. An expected difference between means for two groups for primary and/or permanent caries-affected teeth was set at 1.3 (variance equal to 5.0) because the previous study revealed such a difference [16]. Power of the test was set at $80 \%$ and confidence level at $95 \%$. With such assumptions required sample size for each group was equal to $n=47$.

\section{Oral examination}

The dental examination was performed with the use of artificial light, a plane mirror and a ball-ended dental probe (WHO CPI probe). Decayed, missing and filled primary and permanent teeth ( $\mathrm{dmft}$, DMFT) were assessed according to the recommended criteria of the World Health Organization (WHO) [20]. Caries experience was expressed as the sum of caries-affected primary and permanent teeth because different number of participants in both iNS and control groups had exclusively primary (11 vs 10 participants), mixed (28 vs 22 participants) or permanent dentition (8 vs 15 participants, respectively). In order to evaluate oral hygiene, two indices were used - the Simplified Oral Hygiene Index (OHI-S) obtained by summation of Debri Index (DI) and Calculus Index (CI), by Green and Vermillion, 1964 [21] and the Approximal Plaque Index - API, by Lange et al., 1974 [22]. The used categorization of OHI-S scores was as follows: $0-1.2$ good, $1.3-3.0$ fair, 3.1-6.0 poor oral hygiene, and for DI-S and CI-S 0-0.6 good, 0.7-1.8 fair and 1.9-3.0 poor oral hygiene. The criteria of API value were: < $25 \%$ optimal, $25-39 \%$ quite good, $40-69 \%$ moderate and $70-100 \%$ poor oral hygiene. The periodontal condition was assessed according to the Gingival Index - GI by Löe and Silness, 1963 [22] which evaluates the severity of gingivitis, where the values in the range of $0.1-1.0$ point on mild, $1.1-2.0$ moderate and $2.1-3.0$ severe gingivitis. Presence of enamel hypoplasia was scored according to the modified Developmental Defects of Enamel (mDDE) index [23]. No oral mucosal lesions were found in all participants.
The assessment of oral condition was carried out by examiners, being pediatric dentists (AW-K, KJ, MM-D, IP), that were calibrated by an experienced supervisor (UK) before the study (all of them have been working in the Department of Conservative Dentistry and Pedodontics). Cohen's kappa scores for intra- and interexaminer reliability were $>0.80$ [24].

\section{Cariogenic bacteria assessment in saliva}

In stimulated mixed saliva, counts of Streptococcus mutans (SM) and Lactobacillus spp. (LB) were assessed using a CRT bacteria test (Vivadent Ivoclar). Saliva stimulated by chewing paraffin pellet was collected in a plastic container followed by mouth rinsing with used of distilled water. The both agar carrier surfaces of the test were wet with saliva. The test vial was closed and placed in the incubator at $37^{\circ} \mathrm{C}$ for $48 \mathrm{~h}$. The density of SM and LB colonies were compared with model chart. Results of $10^{5} \mathrm{CFU}$ (colony forming unit) or more of SM and LB indicate a high caries risk [25].

\section{Questionnaire}

The designed questionnaire for this study contained 12 standard items on demographic and social background (gender, parent's education, economic status), utilization of dental care, oral health related behaviors (frequency of tooth brushing, usage of fluoridated toothpaste and other fluoride products and consumption of sugary food and beverages (Supplementary file 1). Economic status was categorized in view of the total family income, the number of family members and the national average salary (Supplementary file 2).

\section{Statistical analysis}

The obtained data were analyzed using Pearson's chisquared test or Fisher's exact test for sociodemographic and practices variables. Normality was analyzed using the Shapiro-Wilk test and was verified using the Student's $t$ test (for independent variables) or the MannWhitney $U$ test (for data with a non-normal distribution) along with the Spearman's rank correlation coefficient with the help of Statistica v. 13.0 PL StatSoft software (StatSoft Poland). For all statistical tests, the significance level was set at $P<0.05$. Cohen's kappa statistics was used to determine the inter- and intra-examiner reliability in caries and enamel hypoplasia diagnosis, oral hygiene and gingival status assessment [24].

\section{Results}

\section{Distribution of the participants}

Ninety-four participants were enrolled to the study, half of them were with idiopathic steroid-sensitive nephrotic syndrome and the remainders were healthy. The disease was diagnosed between the ages of 4 and 15 years (mean 
$3.8 \pm 3.0$ years old), duration of the disease at the time of the study ranged from 2 to 15 years (mean $6.4 \pm 4.0$ years), and number of relapses from 1 to 15 (mean $3.8 \pm$ 2.9).

The mean age in the iNS group was $9.6 \pm 3.9$ years and in the controls $10.8 \pm 3.7$ years, and did not differ significantly. Economic status of the family and number of children were similar in both groups. More mothers and fewer fathers of the iNS participants had secondary or higher level of education (Table 1).

\section{Oral health parameters}

Inter- and intra-examiner reproducibility of the oral clinical examination parameters, on the average, was 0.9 (Cohen's kappa coefficient). The participants suffering from iNS compared to the controls revealed some lower caries experience $(83.0 \%$ vs $95.7 \%)$ and a slightly smaller number of caries affected primary and/or permanent teeth $(4.6 \pm 3.5$ vs $6.0 \pm 4.1)$. The iNS patients had over a 3 -fold lower number of filled teeth than healthy $(P<$ $0.001)$ and similar numbers of decayed and missing primary and/or permanent teeth (Table 2).

Regarding caries-affected permanent teeth, significantly lower DMFT and FT values were found in iNS patients than the controls $(P=0.047$ and $P=0.018$, respectively). However, there was no significant difference in caries experience of primary teeth between the two groups (Table 2). In the iNS group, the number of caries-affected teeth (dmft/DMFT) was positively moderately correlated with a DI-OHI-S value $(\mathrm{r}=0.337, P=$ 0.021). While in healthy participants, a significant moderate correlation between DI-OHI-S and $\mathrm{dt} / \mathrm{DT}$ values ( $\mathrm{r}=0.425, P=0.003)$ was noticed [26].

Among the various types of developmental defects of enamel, only hypoplastic lesions in the examined participants were noticed. The prevalence of enamel hypoplasia was over 7 times higher in the iNS compared to the control group $(\mathrm{P}<0.001)$ and, on average, 8 -fold more teeth were affected $(p<0.001)$ (Table 2$)$.

As for oral hygiene, a higher mean of OHI-S and DI-S scores was found in the iNS group compared to the control group; however, API values were only slightly higher (Table 2). Analysis of distribution of oral hygiene levels showed that 19 iNS participants (40.4\%) and 34 controls (72.3\%) had good oral hygiene according to OHI-S criteria, $17(36.2 \%)$ and $26(55.3 \%)$ optimal or quite good by API scores (Fig. 1). In both groups API values were positively moderately correlated with the number of caries-affected teeth $(\mathrm{r}=0.371, P=0.010$ and $\mathrm{r}=0.398$, $P=0.005)$.

Regarding gingival condition a 2-fold higher mean GI value was found in the iNS patients compared to the controls $(P=0.050)$. However, in both groups the mean GI scores were within the limit of mild gingivitis (Table

Table 1 Characteristics of the studied participants

\begin{tabular}{|c|c|c|c|c|c|c|}
\hline & & \multicolumn{2}{|c|}{ iNS } & \multicolumn{2}{|c|}{ Control } & \multirow{2}{*}{$\begin{array}{l}P \\
\text { value }\end{array}$} \\
\hline & & $n$ & $\%$ & $\mathrm{n}$ & $\%$ & \\
\hline \multirow[t]{2}{*}{ Gender } & male & 25 & 53.2 & 18 & 38.3 & 0.147 \\
\hline & female & 22 & 46.8 & 29 & 61.7 & \\
\hline Age & mean SD & \multicolumn{2}{|c|}{$9.6 \pm 3.9$} & \multicolumn{2}{|c|}{$10.8 \pm 3.7$} & 0.142 \\
\hline \multirow[t]{4}{*}{ Family economic status } & high & 4 & 8.5 & 10 & 21.3 & 0.164 \\
\hline & moderate & 34 & 72.4 & 24 & 51.1 & \\
\hline & satisfactory & 7 & 14.9 & 11 & 23.4 & \\
\hline & unsatisfactory & 2 & 4.2 & 2 & 4.2 & \\
\hline \multirow[t]{4}{*}{ Children's number in the family } & 1 & 11 & 23.4 & 13 & 27.7 & 0.250 \\
\hline & 2 & 21 & 44.7 & 26 & 55.3 & \\
\hline & 3 & 11 & 23.4 & 4 & 8.5 & \\
\hline & $4+$ & 4 & 8.5 & 4 & 8.5 & \\
\hline \multirow[t]{3}{*}{ Father's education } & higher & 8 & 17.0 & 12 & 25.5 & $0.030^{*}$ \\
\hline & secondary & 15 & 31.9 & 20 & 42.6 & \\
\hline & primary & 24 & 51.1 & 15 & 31.9 & \\
\hline \multirow[t]{3}{*}{ Mother's education } & high & 11 & 23.4 & 19 & 40.4 & $0.029^{*}$ \\
\hline & secondary & 25 & 53.2 & 18 & 38.3 & \\
\hline & primary & 11 & 23.4 & 10 & 21.3 & \\
\hline
\end{tabular}


Table 2 Oral health parameters

\begin{tabular}{|c|c|c|c|c|c|}
\hline & iNS & & Control & & $P$ value \\
\hline \multirow[t]{3}{*}{ Caries experience } & $\mathrm{n} / \mathrm{N}$ & $\%$ & $n / N$ & $\%$ & 0.070 \\
\hline & $39 / 47$ & 83.0 & $45 / 47$ & 95.7 & \\
\hline & \multicolumn{2}{|l|}{ mean SD } & \multicolumn{2}{|l|}{ mean SD } & \\
\hline Number of caries-affected primary and/or permanent teeth & \multicolumn{2}{|l|}{$4.6 \pm 3.5$} & \multicolumn{2}{|l|}{$6.0 \pm 4.1$} & 0.126 \\
\hline primary and/or permanent decayed teeth & \multicolumn{2}{|l|}{$3.5 \pm 3.2$} & \multicolumn{2}{|l|}{$2.4 \pm 2.4$} & 0.095 \\
\hline primary and/or permanent missing teeth & \multicolumn{2}{|l|}{$0.02 \pm 0.1$} & \multicolumn{2}{|l|}{$0.2 \pm 0.8$} & 0.543 \\
\hline primary and/or permanent filled teeth & \multicolumn{2}{|l|}{$1.1 \pm 1.6$} & \multicolumn{2}{|l|}{$3.5 \pm 3.0$} & $<0.001^{* * *}$ \\
\hline DMFT & \multicolumn{2}{|l|}{$2.40 \pm 3.04$} & \multicolumn{2}{|l|}{$4.21 \pm 4.77$} & $0.047^{*}$ \\
\hline DT & \multicolumn{2}{|l|}{$1.72 \pm 2.71$} & \multicolumn{2}{|l|}{$1.47 \pm 2.37$} & 0.865 \\
\hline MT & \multicolumn{2}{|l|}{$0.02 \pm 0.14$} & \multicolumn{2}{|l|}{$0.17 \pm 0.81$} & 0.851 \\
\hline FT & \multicolumn{2}{|l|}{$0.66 \pm 0.65$} & \multicolumn{2}{|l|}{$2.57 \pm 3.35$} & $0.018^{*}$ \\
\hline $\mathrm{dmft}$ & \multicolumn{2}{|l|}{$2.19 \pm 2.93$} & \multicolumn{2}{|l|}{$1.79 \pm 2.35$} & 0.561 \\
\hline $\mathrm{dt}$ & \multicolumn{2}{|l|}{$1.74 \pm 2.25$} & \multicolumn{2}{|l|}{$0.89 \pm 1.33$} & 0.152 \\
\hline $\mathrm{mt}$ & \multicolumn{2}{|l|}{0} & \multicolumn{2}{|l|}{$0.02 \pm 0.14$} & 0.865 \\
\hline \multirow[t]{2}{*}{$\mathrm{ft}$} & \multicolumn{2}{|l|}{$0.45 \pm 1.33$} & \multicolumn{2}{|l|}{$0.89 \pm 1.43$} & 0.136 \\
\hline & $n$ & $\%$ & $\mathrm{n}$ & $\%$ & \\
\hline \multirow[t]{2}{*}{ Enamel hypoplasia frequency } & 15 & 31.9 & 2 & 4.3 & $<0.001^{* * *}$ \\
\hline & \multicolumn{2}{|l|}{ mean SD } & \multicolumn{2}{|l|}{ mean SD } & \\
\hline Number of teeth with enamel hypoplasia & $0.80 \pm 1.5$ & & $0.10 \pm 0.3$ & & $<0.001^{* * *}$ \\
\hline $\mathrm{OHI}-\mathrm{S}$ & $1.89 \pm 1.59$ & & $1.05 \pm 1.02$ & & $0.010^{* *}$ \\
\hline DI-S & $1.80 \pm 1.55$ & & $0.99 \pm 0.92$ & & $0.011^{*}$ \\
\hline $\mathrm{Cl}-\mathrm{S}$ & $0.09 \pm 0.31$ & & $0.06 \pm 0.26$ & & 0.463 \\
\hline API (\%) & $54.0 \pm 35.7$ & & $43.4 \pm 27.6$ & & 0.108 \\
\hline Gl & $0.7 \pm 1.0$ & & $0.3 \pm 0.6$ & & 0.050 \\
\hline CFU Streptococcus mutans (SM) & & & & & \\
\hline$<10^{5}$ & 36 & 76.6 & 39 & 83.0 & 0.441 \\
\hline$\geq 10^{5}$ & 11 & 23.4 & 8 & 17.0 & \\
\hline CFU Lactobacilli spp. (LB) & & & & & \\
\hline$<10^{5}$ & 28 & 59.6 & 27 & 57.4 & 0.834 \\
\hline$\geq 10^{5}$ & 19 & 40.4 & 20 & 42.6 & \\
\hline
\end{tabular}

Abbreviations: dmft Number of decayed, missing due to caries and filled primary teeth; DMFT Number of decayed, missing due caries and filled permanent teeth, OHI-S Simplified Oral Hygiene Index, DI Debris index, Cl Calculus index, API Approximal plaque index, GI Gingival index, CFU Colony forming unit, iNS Idiopathic nephrotic syndrome

*- significant difference at $P<0.05$

**- significant difference at $P<0.01$

*** - significant difference at $P<0.001$

2). Analysis of GI values among the studied participants showed that 29 iNS patients (61.7\%) had clinically sound gingival tissues, 4 (8.5\%) mild, 10 (21.3\%), moderate and $4(8.5 \%)$ severe gingivitis. In the controls the figures were 36 (76.6\%), 7 (14.9\%), 4 (8.5\%) and zero, respectively (Fig. 2). In the iNS group, GI values were positively moderately correlated with DI-S and API values $(r=$ $0.456, P=0.001, \mathrm{r}=0.341, P=0.018$, respectively), however, in the control group only with DI-S $(r=0.393, P=$ 0.006; positive moderate correlation).
The percentage of participants with low and high count levels of Streptococcus mutans and Lactobacillus spp. in saliva did not differ significantly between the iNS and control groups (Table 2).

Regarding oral hygiene practice, significantly fewer iNS participants brushed their teeth twice a day compared to the controls; however, both groups used fluoridated toothpastes with similar frequency. There was no difference between the study groups in terms of the last dental visit and its cause. The iNS participants more frequently consumed three or more snacks per day than 


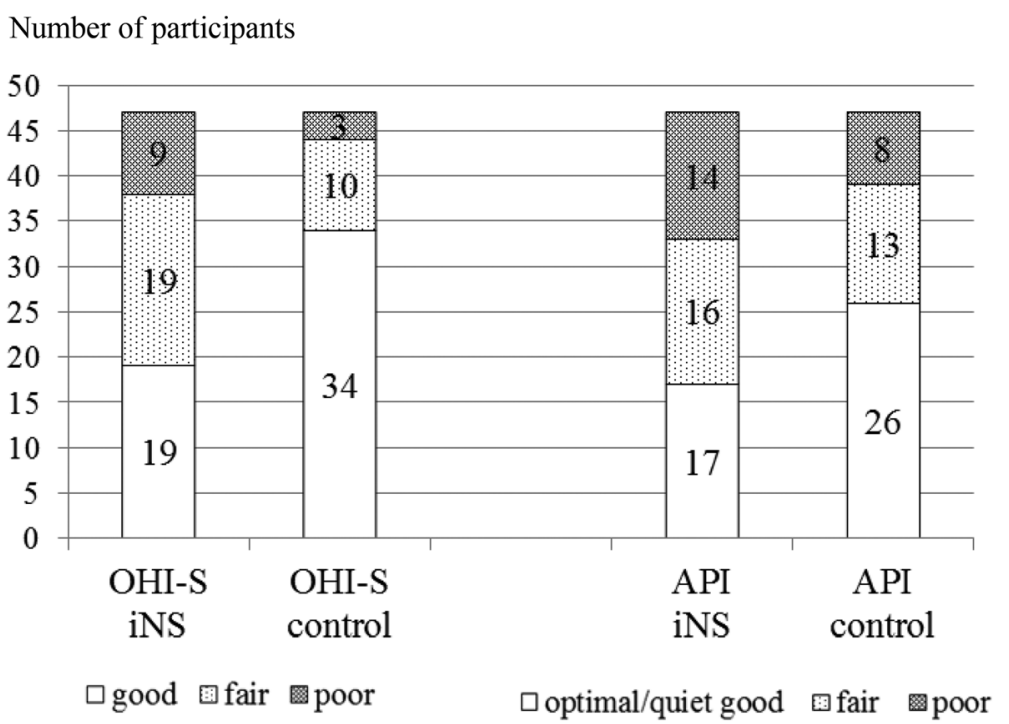

Fig. 1 Distribution of participants with oral hygiene levels according to OHI-S and API indices

the controls $(56.3 \%$ vs $23.4 \%, P=0.002)$ but both ingested sweets and sweetened beverages with similar frequency (Table 3).

\section{Discussion}

The null hypothesis was rejected, as there were differences in the studied oral parameters between two groups. This study showed some lower caries experience in the iNS participants compared to healthy ones $(83.0 \%$ vs $95.7 \%)$. Like Güzel et al. [17] in pediatric patients with nephrotic syndrome in remission phase, we found some lower dmft and DMFT values in iNS patients compared to the controls. On the contrary, another study presented significantly higher $\mathrm{dmft}$ and slightly lower
DMFT values compared to the controls [16]. The higher number of unfilled tooth decays in the iNS patients compared to the controls could be the result of the neglect of dental condition due to continuous care of the general health of children as significantly fewer of them brushed their teeth twice a day.

The number of iNS and healthy participants with high levels of Streptococcus mutans and Lactobacillus spp. did not differ in our study, which could point to a similar caries risk. Other study presented significantly less frequent the isolation of Streptococcus mutans from children with chronic renal failure compared with the controls [14]. Contrary, Takeuchi et al. [27] assessing cariogenic bacteria with use of Dentocult test in patients

Number of participants with gingivitis

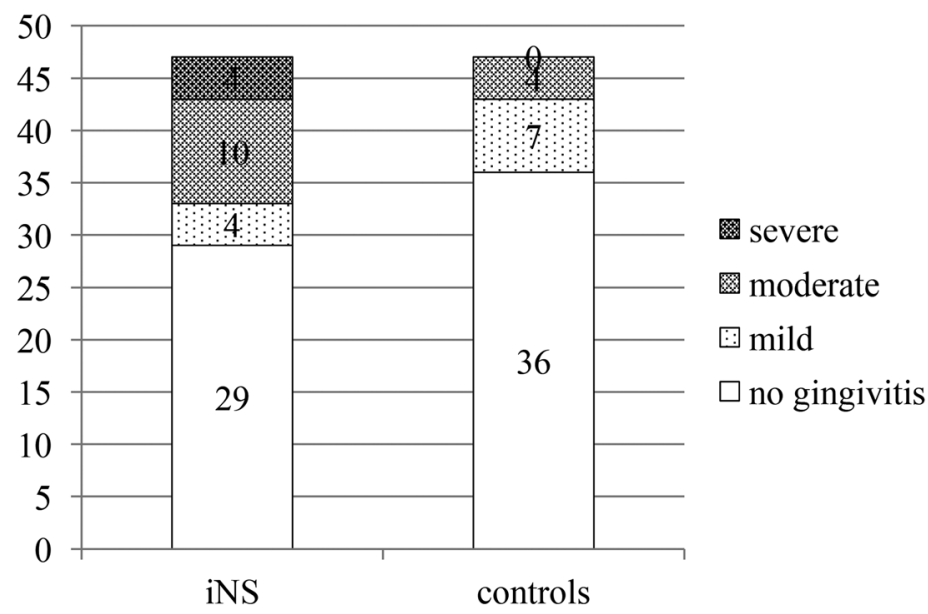

Fig. 2 Distribution of participants with gingivitis 
Table 3 Oral hygiene, dietary habits and utilization of dental care

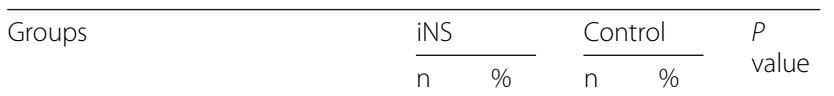

\begin{tabular}{|c|c|c|c|c|c|}
\hline \multicolumn{6}{|l|}{ Tooth brushing } \\
\hline Twice a day & 37 & 78.8 & 44 & 93.6 & \multirow[t]{2}{*}{$0.026^{*}$} \\
\hline Once a day or every few days & 10 & 21.2 & 3 & 6.4 & \\
\hline \multicolumn{6}{|l|}{ Dentifrice } \\
\hline Fluoridated & 43 & 91.5 & 42 & 89.4 & \multirow[t]{2}{*}{0.603} \\
\hline No fluoride & 4 & 8.5 & 5 & 10.6 & \\
\hline \multicolumn{6}{|l|}{ Frequency of sweets consumption } \\
\hline Several times a day & 11 & 23.4 & 13 & 27.7 & \multirow[t]{4}{*}{0.401} \\
\hline Once a day & 20 & 42.6 & 21 & 44.7 & \\
\hline Once a week & 10 & 21.3 & 12 & 25.5 & \\
\hline Once a month & 6 & 12.7 & 1 & 2.1 & \\
\hline \multicolumn{6}{|c|}{ Frequency of drinking sweetened beverages } \\
\hline Several times a day & 13 & 27.6 & 11 & 23.4 & \multirow[t]{4}{*}{0.312} \\
\hline Once a day & 11 & 23.4 & 14 & 29.8 & \\
\hline Once a week & 4 & 8.5 & 7 & 14.9 & \\
\hline Once a month & 19 & 40.5 & 15 & 31.9 & \\
\hline \multicolumn{6}{|l|}{ Number of snacks a day } \\
\hline One & 4 & 8.5 & 2 & 4.3 & \multirow[t]{3}{*}{$0.002^{*}$} \\
\hline Two & 18 & 38.3 & 34 & 72.3 & \\
\hline Three and more & 25 & 53.2 & 11 & 23.4 & \\
\hline \multicolumn{6}{|l|}{ Last dental visit } \\
\hline Within 6 months & 36 & 76.6 & 42 & 89.4 & \multirow[t]{3}{*}{0.204} \\
\hline 12 months & 9 & 19.1 & 5 & 10.6 & \\
\hline Does not remember & 2 & 4.3 & 0 & 0 & \\
\hline \multicolumn{6}{|l|}{ Cause of last dental visit } \\
\hline Pain & 6 & 12.8 & 0 & 0 & \multirow[t]{4}{*}{0.901} \\
\hline Decay & 17 & 36.2 & 23 & 48.9 & \\
\hline Control & 19 & 40.4 & 19 & 40.5 & \\
\hline Other cause & 5 & 10.6 & 5 & 10.6 & \\
\hline \multicolumn{6}{|c|}{ Topical professional application of fluoride specimens } \\
\hline Yes & 16 & 34.0 & 17 & 36.2 & \multirow[t]{2}{*}{0.541} \\
\hline No or does know & 31 & 66.0 & 30 & 63.8 & \\
\hline
\end{tabular}

Abbreviation: iNS Idiopathic nephrotic syndrome

*- significant difference at $P<0.05$

**- significant difference at $P<0.001$

with renal disease found a significantly higher bacterial counts compared to healthy controls and suggested a higher caries risk development in the patients.

The significantly worse oral hygiene in the iNS group compared to the controls based on the mean score of $\mathrm{OHI}-\mathrm{S}$ in our study was found. Another study assessing oral hygiene with use of Plaque Index - PLI (by SilnessL e) could confirm our finding as significantly higher score value in children suffering from nephrotic syndrome compared to the healthy ones was noticed [6].

Deterioration of defense mechanisms in nephrotic syndrome results from hyperlipidemia and immunosuppressive impact of taken medications, including steroids. All children from India suffering from nephrotic syndrome presented inflammation of gingival tissues, assessed by the Modified Gingival Index by Lobene. Contrarily, our data based on the Gingival Index (by Löe and Silness) showed clinically healthy gingiva in 29 (61.7\%) of iNS participants. Our iNS patients revealed some higher mean GI scores compared to the control group, unlike other results, where the difference was significant [6]. Angelova [28] found over a 2-fold higher GI value compared to our data (1.59 vs 0.7 ).

Gingival inflammation is caused by dental plaque accumulation due to poor oral hygiene, which confirmed our data. Attention directed to medical care, frequent hospitalization resulting from relapses of the disease and hypoplastic teeth leaning towards dental biofilm accumulation could be the causes of higher dental plaque scores in the iNS patients. However, immunosuppression associated with treatment of nephrotic syndrome may alter the inflammatory response of gingival tissue to bacterial plaque. In addition, gingivitis may mask the pallor caused by anemia being a systemic manifestation of altered renal function [29].

The age at which the first disease episode occurs, correlates with the abnormality development of emerging dental enamel at the time. We found that the iNS onset in 43 patients occurred between 2 and 8 years of age, i.e. within the period of enamel formation in permanent teeth, which lasts approximately from 3 (first molars) to 7-8 years (second molars) when dental crowns (enamel) are completed [30]. Therefore, enamel disturbances could develop in these patients; however, we noticed enamel hypoplasia in 15 participants. Nevertheless, enamel hypoplasia occurred approximately seven times more often in the patients with nephrotic syndrome than in the controls, and the defects involved eight times more teeth. Bublitz et al. [31] observed enamel hypoplasia in $20 \%$ of patients with steroid-sensitive nephrotic syndrome, which was lower compared to our result (31.9\%). However, another study showed that only 1 out of 38 patients (i.e. $2.6 \%$ ) was affected by enamel hypoplasia [17].

Long-term effective measures of dental plaque control should be implemented to avoid the risk of caries development and gingival inflammation. Early diagnosis and prompt management of carious lesions are compulsory to avoid extensive dental treatment and potential infection foci from the oral cavity. Additionally, treatment of enamel hypoplasia should be performed when severe 
defects are present due to dental plaque retention and esthetics.

Collaboration between dentists and pediatric nephrologists, and better understanding of the interrelationship between systemic and oral abnormalities are required in dental care of patients with nephrotic syndrome. The dentist should also consider the adverse side effects of drug therapy and appropriate prescribing medications, in view of compromised renal function. Considering the chronic course of the disease, maintenance of oral health is important. In the majority of the iNS patients, the disease does not complicate dental care. The dental treatment of patients in remission period of the disease can be carried out regularly at that time. However, surgical procedures should be performed with suitable antibiotic cover and consultation with the nephrologist [32, 33].

The present study has some limitations and the results should be interpreted in the context of its design. It included a small number of participants who represented only a fraction of the total number of pediatric patients with idiopathic nephrotic syndrome and self-reported by parents' questionnaires concerning factors influencing oral health. The strength was that calibrated dentists examined the participants and a control group of healthy participants was included.

The future prospective study seems to be needed to elucidate an impact of the disease and its treatment on oral health condition of the patients with respect to modifiable risk factors for oral diseases that act locally.

\section{Conclusions}

The iNS patients despite the poor oral hygiene revealed lower caries experience but smaller number of restored caries-affected teeth, more severe gingivitis and more frequently teeth affected by enamel hypoplasia compared to the controls.

\section{Supplementary information}

Supplementary information accompanies this paper at https://doi.org/10. 1186/s12903-020-01197-1.

Additional file 1: Supplementary file 1. Table 3 Oral hygiene, dietary habits and utilization of dental care. Description of data: How often your child brushes his/her teeth: twice a day; once a day; every few days. Does your child use fluoridated toothpaste: yes, not. How often your child eats sweets (e.g. candies, chocolate, chocolate bar, cakes, sweet bun, donut, chips): several times a day, once a day, once a week, once a month. How often your child drinks sweetened beverages (e.g. coca-cola, pepsi cola, fanta, lemonade, tea beverages with added sugar). How many snacks your child eats a day: one, two three and more. When was last dental visit of your child: within last six months; 12 months ago, I do not remember. What was a cause of the last dental visit of your child: a tooth pain, tooth decay, control, others (e.g. continuation of dental treatment, unaesthetic appearance of teeth). Did your child had application of fluoride varnish, gel or foam in a dental office; yes, no, I do not know.

Additional file 2: Supplementary file 2. Table 1 Characteristics of the studied participants. Description of data: Children' number of in the family: 1, 2, 3, 4, 5 or more, specify and mark. Family economic status: $\geq$ 2001 zloty (high), 1693-2000 zloty (moderate), 1000-1692 zloty (satisfactory), $\leq 999$ zloty (unsatisfactory). Father education (years of schooling): 10 (primary), 14-15 (secondary), 16-20 (high). Mother education (years of schooling): 10 (primary), 14-15 (secondary), 16-20 (high). *Family economic status was calculated based on the division of total family monthly income in zloty (father and mother) by number of the family members in respect to a national average income per family member, which was 1693 PLN in 2018.

\section{Abbreviations}

DMFT: Decay, missing and filled permanent teeth; dmft: Decay, missing and filled primary teeth; mDDE: Modified Developmental Defects of Enamel; OHIS: Simplified Oral Hygiene Index; DI: Debri Index; Cl: Calculus Index; API: Approximal Plaque Index; PLI: Plaque Index; Gl: Gingival Index; SM: Streptococcus mutans; LB: Lactobacillus spp; CFU: Colony forming unit; eGRF: Estimated glomerular filtration rate; WHO: World Health Organization; iNS: Idiopathic nephrotic syndrome

\section{Acknowledgements \\ The authors thank the children and adolescents and their parents for participation in the study.}

\section{Authors' contributions}

AWK, KJ, MMD and IP performed the dental clinical examination, collected the questionnaire data and bacterial test. KP performed the medical examination and gathered the blood parameters. IK performed medical examination and drafting. UK and IM designed the study, performed analysis and interpretation of the data, drafted and edited the manuscript. All authors read and approved the final manuscript.

\section{Funding}

This work was supported by a grant from the Wroclaw Medical University, Poland (grant no ST-B010.16.044).

\section{Availability of data and materials}

The datasets used and analyzed during the current study are available from the corresponding author on request.

\section{Ethics approval and consent to participate}

The study protocol was approved by the Bioethics Committee of Wroclaw Medical University (permission no. KB-343/2016) in accordance with the Declaration of Helsinki. Participation in the study was voluntary and anonymous, and the collected data was treated confidentially. Written informed consent was obtained from a parent or guardian for participants under 16 years old.

\section{Consent for publication}

Not applicable.

\section{Competing interests}

The authors declare that they have no competing interests related to this study

\section{Author details}

1Department of Conservative Dentistry and Pedodontics, Wroclaw Medical University, Krakowska 26, 50-425 Wroclaw, Poland. ${ }^{2}$ Department and Clinic of Pediatric Nephrology, Wroclaw Medical University, Borowska 213, 50-556 Wroclaw, Poland.

Received: 8 March 2020 Accepted: 15 July 2020

Published online: 29 July 2020

\section{References}

1. Eddy AA, Symons JN. Nephrotic syndrome in children. Lancet Lond Engl. 2003;369:629-39.

2. Meyrier A, Niaudet P. Acute kidney injury complicating nephrotic syndrome of minimal change disease. Kidney Int. 2018;94:861-9.

3. Pasini A, Benetti E, Conti G, Ghio L, Lepore M, Massella L, et al. The Italian Society for Pediatric Nephrology (SINePe) consensus document on the 
management of nephrotic syndrome in children: Part I - Diagnosis and treatment of the first episode and the first relapse. Ital J Pediatr. 2017;43. https://doi.org/10.1186/s13052-017-0356-x.

4. Noone DG, lijima K, Parekh R. Idiopathic nephrotic syndrome in children Lancet Lond Engl. 2018;392:61-74.

5. Kidney Disease:Improving Global Outcomes (KDIGO) Gromeluronephritis Work Group. KDIGO Clinical Practice Guldeline for Glomerulonephritis. Kidney Inter. 2012;2:139-274. https://doi.org/10.1038/kisup.2012.12 https:// kdigo.org/wp-content/uploads/2017/02/KDIGO-2012-GN-Guideline-English pdf.

6. Olczak-Kowalczyk D, Pyrżak B, Dąbkowska M, Pańczyk-Tomaszewska M, Miszkurka G, Rogozińska I, et al. Candida spp. and gingivitis in children with nephrotic syndrome or type 1 diabetes. BMC Oral Health. 2015;15:57.

7. Beeraka SS, Natarajan K, Patil R, Manne RK, Prathi VS, Kolaparthi VSK. Clinical and radiological assessment of effects of long-term corticosteroid therapy on oral health. Dent Res J. 2013;10:666-73.

8. El-Mashad GM, El-Hawy MA, El-Hefnawy SM, Mohamed SM. Bone mineral density in children with idiopathic nephrotic syndrome. J Pediatr. 2017; 93(2):142-7. https://doi.org/10.1016/j.jped.2016.05.010.

9. Hong L, Levy SM, Warren JJ, Dawson DV, Bergus GR, Wefel JS. Association of amoxicillin use during early childhood with developmental tooth enamel defects. Arch Pediatr Adolesc Med. 2005;159:943-8.

10. Mihalaş E, Matricala L, Chelmuş A, Ghețu N, Petcu A, Paşca S. The role of chronic exposure to amoxicillin/Clavulanic acid on the developmental enamel defects in mice. Toxicol Pathol. 2016;44:61-70.

11. Esmaeeili M, Azarfar A, Hoseinnalizadeh S. Calcium and Vitamin D metabolism in pediatric nephrotic syndrome: An update on the exiting literature. Int J Pediatr. 2015:3(2.1):103-9.

12. van der Tas JT, Elfrink MEC, Heijboer AC, Rivadeneira F, Jaddoe WW Tiemeier $\mathrm{H}$, Schoufour JD, Moll HA, Ongkosuwito EM, Wolvius EB, Voortman T. Foetal, neonatal and child vitamin D status and enamel hypomineralization. Community Dent Oral Epidemiol. 2018;46:343-51.

13. Koch MJ, Brührer R, Pioch T, Schärer K. Enamel hypoplasia of primary teeth in chronic renal failure. Pediatr Nephrol. 1999;13:68-7.

14. Al Novaiser A, Roberts GJ, Trompeter RS, Wilson M, Lucas VS. Oral health in children with chronic renal failure. Pediatr Nephrol. 2003;18:39-45.

15. Gupta M, Gupta M, Abiskek. Oral condition in renal disorders and treatment consideration - a review for pediatric dentist. Saudi Dent J. 2015;27:113-9.

16. Piróg A, Michałek-Pasternak E, Mizerska-Wasiak M, Pańczyk-Tomaszewska M, Domagała J, Roszkowska-Blaim M, et al. The incidence and intensity of dental caries in children with nephrotic syndrome. Nowa Stomatol. 2012;3: 91-6.

17. Güzel KGU, Yilmaz D, Abacigil F, Pirinçci S. Oral aspects in children with nephrotic syndrome. Turk Klin J Dent Sci. 2018;24:183-9.

18. The PLOS Medicine Editors. Observational studies: getting clear about transparency. PLoS Med. 2014;11(8):e1001711. https://doi.org/10.1371/ journal.pmed.1001711.

19. Select statistical services. Comparing two means - sample-size. https:// select-statistics.co.uk/calculators/sample-size-calculator-two-means/. Accessed 30 Apr 2020

20. World Health Organization. Oral health surveys - basic methods. 5th ed 2013. http://www.who.int/oral_health/publications/9789241548649/en/ Accessed 22 Apr 2020

21. the Simplified Oral Hygiene Index (OHI-S by Greene and Vermilion, 1964). https://capp.mau.se/methods-and-indices/ Accessed 22 Apr 2020

22. Wolf HF, Rateitschak EM, Rateitschak KH, Hassel TM. Periodontologie. In: Rateitschak KH, Wolf HF, editors. Color atlas of dental medicine. 3rd ed. New York: George Thieme Stuttgart; 2005. p. 68-9.

23. Clarkson J, O'Mullane D. A modified DDE index to use in epidemiological studies of enamel defects. J Dent Res. 1989;68:445-50.

24. GraphPad QuickCals. https://www.graphpad.com/quickcalcs/kappa1/. Accessed 30 Apr 2020

25. Ivoclar Vivadent CRT bacteria User Manual. https://www.manualsdir.com/ manuals/773888/ivoclar-vivadent-crt-bacteria.html. Accessed 30 Apr 2020.

26. Akoglu H. User's guide to correlation coefficients. Turk J Emerg Med. 2018 18(3):91-3. https://doi.org/10.1016/j.tjem.2018.08.001.

27. Takeuchi Y, Ishikawa H, Inada M, Shinozuka O, Umeda M, Yamazaki T, Yoshikawa M, Sasaki S. Study of the oral microbial flora in patients with renal disease. Nephrology (Carlton). 2007;12:182-90.

28. Angelova ST. Oral health in children suffering from pyelonephritis and nephrotic syndrome. J Health Hyg. 2018;1:06 https://www.imedpub.com/ articles/oral-health-in-children-suffering-from-pyelonephritis-and-nephroticsyndrome.pdf. Accessed 22 Apr 2020

29. Nakhjavani YB, Bayramy A. The dental and oral status of children with chronic renal failure. J Indian Soc Pedod Prev Dent. 2007;25:7-9.

30. AAPD Oral Health Policies \& Recommendations (Reference Manual): Dental growth and development. https://www.aapd.org/research/oral-healthpolicies\%2D\%2Drecommendations/dental-growth-and-development. Accessed 22 Apr 2020

31. Bublitz A, Machat E, Schärer K, Komposch G, Mehls O. Changes in dental development in paediatric patients with chronic kidney disease. Proc Eur Dial Transplant Assoc. 1981;18:517-23.

32. Proctor R, Kumar N, Stein A, Moles D, Porter S. Oral and dental aspects of chronic renal failure. J Dent Res. 2005;84:199-208.

33. Sulejmanagić $H$, Sulejmanagić N, Prohić S, Šečić S, Mišeljić S. Dental treatment of patients with kidney diseases - review. Bosn J Basic Med Sci. 2005;5:52-6.

\section{Publisher's Note}

Springer Nature remains neutral with regard to jurisdictional claims in published maps and institutional affiliations.
Ready to submit your research? Choose BMC and benefit from:

- fast, convenient online submission

- thorough peer review by experienced researchers in your field

- rapid publication on acceptance

- support for research data, including large and complex data types

- gold Open Access which fosters wider collaboration and increased citations

- maximum visibility for your research: over $100 \mathrm{M}$ website views per year

At BMC, research is always in progress.

Learn more biomedcentral.com/submissions 